\title{
Socioeconomic perspectives on physical activity and aging
}

\author{
Christoph Breuer • Tim Pawlowski
}

Published online: 5 October 2011

(C) European Group for Research into Elderly and Physical Activity (EGREPA) 2011

\section{Introduction}

The European Review of Aging and Physical Activity is a well-established academic journal which has lots of merits for broadening and deepening the body of knowledge with regard to physical activity and aging. On closer inspection, it becomes apparent that most contributions do follow a natural or life science perspective. However, also the social sciences in general and economics and sociology in particular might help in exploring and understanding the relationship between physical activity and aging. This applies for age-related influencing factors on physical activity as well as for age-related effects of physical activity.

\section{Socioeconomic factors influencing physical activity}

Following Andreff [1], the analysis of factors influencing participation in sports and physical activity is considered to be a promising research topic in general. A major reason for this is that managers and politicians might actively stimulate participation decisions of individuals based on the knowledge of factors influencing physical activity.

\section{Theoretical issues}

Following a socioeconomic approach, age is a crucial category for analyzing physical activity. However, age has

C. Breuer $(\bowtie) \cdot$ T. Pawlowski

German Sport University Cologne,

Institute of Sport Economics and Sport Management,

50927 Cologne, Germany

e-mail: Breuer@dshs-koeln.de no explanatory power by itself. Age is just a proxy for all potential age-related influences on physical activity. In this context, four different age factors of physical activity can be differentiated: (1) physical (decreasing health and fitness by age), (2) mental [changing motivation (perception and cognition) towards physical activity by age], (3) social (age norms which shape a social desired ideal of active or inactive aging), and (4) economic age factors (age-related changes in individual time and financial budgets due to age-related critical life events such as starting a family, parenting, starting professional life, and retirement). Moreover, research shows also that the supply of sport facilities (e.g., [17]) and the travel time to the facilities [13] do impact the age-related decision to participate in sport or not, even if it remains unclear whether these effects are pure economic effects or can also traced back to physical or mental factors to a certain extent.

Despite this essential differentiation, most socioeconomic papers on physical activity and aging still just focus on age as a proxy instead of analyzing the meanings behind it. These articles contribute by detecting the correlation between physical activity and aging at a certain point in time, but they are not able to explain that relationship as they do not uncover the effective type of age factor and its significance.

Methodological issues

Furthermore, to understand age effects exactly, it is vital to differentiate between age, period, and cohort effects. Period effects are the influences of historical events and social changes on physical activity and they are responsible for an unstable development of sport and physical activity over time. Age and cohort are affected by period effects. As with age, period is a proxy variable which needs further social 
and economical factors to gain explanatory power. (1) The social period factor includes changes in social norms and values, e.g., new ideals for body mass and slimness. (2) The economic period factor takes into account changes in infrastructural, financial, and temporal resources for sport activity (e.g., changes in sport supply, retirement, unemployment, etc.).

Cohort effects can be described as the influences of historical events and social changes on physical activity, similar to period effects. However, the difference is that cohort effects are cohort-specific, meaning that only a few cohorts (groups with same years of birth) are really affected by the historical events taking place in a certain period and other age groups are not. Like age and period, cohort is a proxy variable with no explanatory power itself. Also in this case, the same social and economic factors apply as in period effects with the difference that they affect the preferences and resources of physical activity only in certain groups with same years of birth.

The central significance of age, period, and cohort effects leads to methodological particularities in lifespan research. Generally, sports activity during the lifespan can be analyzed by four methods: cross-sectional studies, longitudinal analyses, multipoint cross-sectional studies, and cohort sequence analyses. But these methods differ in their capability, which is highest if age, period, and cohort effects are controlled. Cross-sectional studies cannot measure developments because they only control period effects. Age and cohort effects are combined; thus, it remains unexplained whether differences between age groups identified cross-sectionally can be ascribed to age or cohort effects. Therefore, cross-sectional studies can produce ecological fallacies. From results on the macro level (population), conclusions are made concerning laws on the micro level (individual) that do not really exist. In contrast, longitudinal analyses measure development processes and monitor cohort effects. But age and period effects are combined. Thus, it remains unclear whether changes measured over time must be attributed to age or period effects. For this reason, the risk of an ecological fallacy persists in longitudinal analyses, but it is smaller. With the help of multipoint cross-sectional studies, age, period, and cohort effects can be analyzed sufficiently. Indeed, compared to simple cross-sectional studies, there is a small but serious risk of an ecological fallacy, if compared populations are only similar and not the same. For this reason, the appropriate form of analysis in lifespan research is the cohort sequence, which analyzes the same population at several time points. Beginning with the second measuring point, a "youngest" age group is added to each measuring point. In cohort sequence analyses, period and cohort effects can be monitored in contrast to longitudinal analyses. The analysis of one identical population (aside from the youngest age group) leads to a notably smaller risk of an ecological fallacy than in the multipoint crosssectional study.

\section{Contributions to this volume}

The state of research regarding socioeconomic patterns of physical activity and aging is well documented in the European Review of Aging and Physical Activity [3]. This special issue broadens and deepens the body of knowledge as follows: Ruseski et al. extend the economic approaches on physical activity and aging by examining the role played by time constraints and family structure in survey data from Rheinberg, Germany. Based on empirical models that account for the two-part decision-the decision to participate and the decision about how long to participate - they find that time constraints in the form of time spent caring for children and relatives and family structure in the form of the presence of children reduce both the likelihood that individuals participate and the time spent taking part in sports. In a second paper, steinmayr et al. investigate by means of semiparametric econometrics in how far the distance between the next sports facilities and children's homes matter for their sports activities inside and outside of sports clubs. They find that while distance does not matter in larger towns and cities, it does matter in smaller towns and particular on the countryside. Furthermore, tischler et al. provide new insights in the relationship of age, gender, social class, and physical activity.

\section{Effects of physical activity}

In general, the development of sport has become a policy target because of its significance for health care systems and economies in general. For instance, the World Health Organization [16] estimates that up to $50 \%$ of the world's population does not undertake the physical activity required to obtain health benefits. Such inactivity translates into considerable health care costs (e.g., [4]). It follows that if policies can directly affect sports participation (maybe with the knowledge of factors influencing sport participation as mentioned above), then they can help increase health and reduce health care costs.

As mentioned by Langer [11], a couple of other effects are often suggested to result from physical activity. For instance, people accumulate social capital in sport clubs and sports might contribute to social integration or even inclusion of foreigners. However, although often proclaimed by politicians, empirical evidence on such effects is scare since the effects are quite often hardly measureable. As an attempt to measure also the intangible effects of physical activity, recent contributions have tried to combine the field of happiness research and previous approaches in sports science. 


\section{Theoretical issues}

While traditionally investigation of happiness or subjective well-being (SWB) of citizens has been associated with psychologists, Van Praag and Frijters and Kahneman et al. [10, 15] have pioneered the relevance of happiness research in the context of economics as an attempt to measure the "experienced" utility of individuals. Since the consumption of sports is linked to social interactions (e.g., [7]) and relational goods (e.g., [2]), the decision to undertake a sports activity must logically be associated with an increase in the SWB of a rational utility maximizing individual. Therefore, from a theoretical point of view, the combination of happiness research and research on physical activity and sports participation are somewhat logical.

\section{Methodological issues}

Economists (sports economists) usually make use of large-scale data to analyze possible factors influencing SWB. As noted by Forrest and McHale [5] as well as Huang and Humphreys [9], it might well be that some feedbacks exist between SWB and physical activity or sports participation. On one hand, as mentioned in the "Introduction" section, it is rather plausible to expect a positive effect of physical activity on the individual's health status. Since the health status is of importance for SWB, a positive effect of participation in physical activity and sports on SWB is probable. However, bad health conditions might prevent people who are generally willing to participate in physical activity and sports to do so. Therefore, a certain level of physical and mental/psychical health might also be a constraint for individuals participating in sports.

The situation described above is known (in econometric terms) as the challenge of reverse causality. In order to avoid estimation biases from reverse causality, different estimation techniques and strategies have been developed. One possibility is an instrumental variable approach. The aim in the context here can be described as making use of variables that only have an impact on SWB through influencing sports participation. Instrumental variables may not be correlated with the error term of the original model [18].

Contribution to this volume

While growing evidence exists that sports participation increases SWB (e.g., $[12,14])$, there is no study that investigates whether the magnitude of this impact is agespecific. This is surprising since, as mentioned above, sports participation and engagement in physical activity have a strong age-specific profile. Furthermore, previous findings from happiness research suggest a U-shaped relationship between age and SWB, which means that younger and older people are happier compared with middle-aged individuals. For instance, Graham and Pettinato [8] found that individuals living in Latin America have the lowest level of SWB at approximately 50 years of age. In addition, Frey and Stutzer [6] found that people older than 60 years are happier than people aged 30 years and younger.

Consequently, the fourth paper in this special issue by Pawlowski et al. explores the age-specific effects of sports participation on SWB for a broad cross-section of 19 European countries. Their results support previous findings that sports engagement contributes to the SWB of individuals. However, it appears that being generally physically active contributes the more to SWB the older the individuals are. Therefore, policy measures that seek to increase engagement in physical activity among older people are of significance since the net effect on SWB is the highest.

\section{References}

1. Andreff W (2007) New perspectives in sports economics: a European view. In: Klein M-L, Kurscheidt M (eds) Neue Perspektiven ökonomischer Sportforschung. Schorndorf, Hofmann, pp 35-68

2. Becchetti A, Pelloni A, Rossetti F (2008) Relational goods, sociability, and happiness. Kyklos 61(3):343-363

3. Breuer C, Hallmann K, Wicker P, Feiler S (2010) Socio-economic patterns of sport demand and aging. Eur Rev Aging Phys Act 7 (2):61-70

4. Colditz GA (1999) Economic costs of obesity and inactivity. Med Sci Sports Exerc 31(11):663-667

5. Forrest D, McHale I (2009) Public policy, sport and happiness: an empirical study. Salford University, Manchester. Working paper

6. Frey BS, Stutzer A (2000) Happiness, economy and institutions. Econ J 110(466):918-938

7. Frey BS, Stutzer A (2005) Testing theories of happiness. In: Bruni L, Porta PL (eds) Economics and happiness: framing the analysis. Oxford University Press, Oxford, pp 116-146

8. Graham C, Pettinato S (2000) Happiness, markets and democracy: Latin America in comparative perspective. J Happiness Stud 2 (3):237-268

9. Huang H, Humphreys BR (2010) Sports participation and happiness: evidence from U.S. micro data. University of Alberta, Edmonton. Working paper no. 2010-09

10. Kahneman D, Diener E, Schwarz N (1999) Well-being: the foundations of hedonic psychology. Russell, New York

11. Langer M (2006) Öffentliche Förderung des Sports. Eine ordnungspolitische Analyse (Volkswirtschaftliche Schriften, 548). Duncker \& Humblot, Berlin

12. Lechner M (2009) Long-run labour market and health effects of individual sports activities. J Health Econ 28(4):839-854

13. Pawlowski T, Breuer C, Wicker P, Poupaux S (2009) Travel time spending behavior in recreational sports: an econometric approach with management implications. Eur Sport Manag Q 9(3):215-242 
14. Rasciute S, Downward PM (2010) Health or happiness? What is the impact of physical activity on the individual. Kyklos 63 (2):256-270

15. Van Praag BMS, Frijters P (1999) The measurement of welfare and well-being: the Leyden approach. In: Kahneman D, Diener E, Schwarz N (eds) Well-being: the foundations of hedonic psychology. Russel Sage Found, New York, pp 413432
16. WHO (2008) Physical inactivity: a global public health problem. http://www.who.int/dietphysicalactivity/factsheet inactivity/en/index. html

17. Wicker P, Breuer C, Pawlowski T (2009) Promoting sport for all to age-specific target groups - the impact of sport infrastructure. Eur Sport Manag Q 9(2):103-118

18. Wooldridge JM (2010) Econometric analysis of cross section and panel data, 2nd edn. MIT Press, Cambridge 